\title{
Positron Emission Tomography and Single-Photon Emission Computed Tomography in Central Nervous System Drug Development
}

\author{
David J. Brooks \\ Medical Research Council Clinical Sciences Centre and Division of Neuroscience, Faculty of Medicine, Imperial College, \\ Hammersmith Hospital, London W12 ONN, United Kingdom
}

\begin{abstract}
Summary: In this review, the value of functional imaging [positron emission tomography (PET)/single-photon emission computed tomography (SPECT)] in drug development is considered. Radionuclide imaging can help establish the diagnosis of neurodegenerative disorders where this is in doubt and provides a potential biomarker for following drug effects on disease progression. PET and SPECT can help understand mechanisms of disease and determine the functional effects of therapeutic approaches on neurotransmission and metabolism. Synthesizing radiotracer analogs of novel drugs can provide proof of principle that these agents reach their enzyme or receptor targets and delineate their regional brain distribution. If such radiotracers do not prove to have ideal properties for
\end{abstract}

imaging, the concept of microdosing potentially allows multiple other drug analogs to be tested with less stringent regulatory requirements than for novel medicinals. Finally, PET tracers can provide receptor and enzyme active site dose occupancy profiles, thereby guiding dosage selection for phase 1 and phase 2 trials. The eventual hope is that radiotracer imaging will provide a surrogate marker for drug efficacy, although this has yet to be realized, and progress the concept of personalized medicine where receptor/enzyme binding profiles help predict therapeutic outcome. Key Words: Positron emission tomography/PET, SPECT, drug development, Alzheimer/Parkinson, neuroprotection, dose occupancy.

\section{INTRODUCTION}

Positron emission tomography (PET) and single-photon emission computed tomography (SPECT) provide a means of examining regional cerebral blood flow, metabolism, and pharmacology in vivo under both resting and activating conditions. These molecular imaging techniques rely on radiolabeled molecules (tracers) that bind to enzyme sites or surface receptors. PET utilizes shortlived positron emitting isotopes $\left({ }^{15} \mathrm{O},{ }^{11} \mathrm{C},{ }^{18} \mathrm{~F},{ }^{76} \mathrm{Br}\right)$, whereas SPECT uses lower energy $\gamma$-emitting isotopes $\left({ }^{123} \mathrm{I},{ }^{99 \mathrm{~m}} \mathrm{Tc}\right)$. Both techniques can detect nanomoles of tracer, but PET has the advantage that it is more sensitive and versatile and allows scatter correction to be performed. SPECT is, however, cheaper and more widely available as it does not rely on a local cyclotron for production of isotopes. A list of some of the neurotrans-

Address correspondence and reprint requests to David J. Brooks, M.D. DSc. FRCP FMed Sci, Hartnett Professor of Neurology, Imperial College London, Cyclotron Building, Hammersmith Hospital, Du Cane Road, London W12 0NN, UK. E-mail: david.brooks@csc.mrc.ac.uk. mitter systems now amenable to study and the more commonly employed radiotracers is detailed in Table 1 .

To derive information about the integrity of neurotransmitter systems from the time course of regional cerebral tracer uptake and arterial plasma activity, it is necessary to use a kinetic model describing the tracer distribution between different physical and metabolic compartments. PET detects $511 \mathrm{keV}$ photons and so cannot distinguish native tracer activity from that of a metabolite. Fortunately, most of the ligands used as PET tracers are not metabolized significantly by brain tissue. The rate of plasma tracer metabolite formation can be determined using serial HPLC measurements enabling a metabolite-corrected input function to be generated.

\section{KINETIC MODELING}

Traditionally, brain uptake of PET tracers has been described using compartmental modeling. The simplest approaches assume that brain regions contain a nonspecific freely exchanging compartment and a compartment where tracer is bound specifically; see Figure 1. A brain 
TABLE 1. Radiotracers Available for Studying Neuropharmacology

Biological Application

Blood flow

Oxygen metabolism

Glucose metabolism

Dopamine storage/DDC activity

Monoamine vesicle transporters

Dopamine transporters (DAT)

Dopamine D1 type sites

Dopamine D2 type sites

Noradrenaline transporters

Noradrenaline $\alpha 2$

Serotonin storage

Serotonin transporters

Serotonin $\mathrm{HT}_{1 \mathrm{a}}$

Serotonin $\mathrm{HT}_{2 \mathrm{a}}$

Acetylcholinesterase activity

Cholinergic vesicle transporters

Muscarinic M1 sites

Nicotinic sites

Histamine $\mathrm{H} 1$ sites

Opioid $\mu$ sites

Opioid $\mu, \kappa$, and $\delta$ sites

Central benzodiazepine sites

Central benzodiazepine sites ( $\alpha 5$ subunits)

Peripheral benzodiazepine sites

Substance P/NK1 sites

Adenosine $\mathrm{A}_{2 \mathrm{~A}}$ sites

NMDA voltage channels

Amyloid

Phosphoglycoprotein activity
Tracers

$\mathrm{H}_{2}{ }^{15} \mathrm{O},{ }^{15} \mathrm{O}$-butanol. ${ }^{99 \mathrm{~m}} \mathrm{Tc}-\mathrm{HMPAO},{ }^{133} \mathrm{Xe}$

${ }^{15} \mathrm{O}_{2}$

${ }^{18} \mathrm{~F}$-2-fluoro-2-deoxyglucose (FDG)

${ }^{18} \mathrm{~F}$-6-fluorodopa (F-dopa), $\beta-{ }^{11} \mathrm{C}$-dopa

${ }^{11} \mathrm{C}$-dihydrotetrabenazine (DTBZ)

${ }^{11} \mathrm{C}$-CFT, ${ }^{11} \mathrm{C}$-RTI $32,{ }^{18} \mathrm{~F}-\mathrm{CFT},{ }^{123} \mathrm{I}-\beta$-CIT

${ }^{123}$ I-FP-CIT, ${ }^{123}$ I-IPT, ${ }^{123}$ I-altropane

${ }^{11} \mathrm{C}-\mathrm{SCH} 23390$

${ }^{11} \mathrm{C}$-raclopride, ${ }^{11} \mathrm{C}$-FLB456, ${ }^{11} \mathrm{C}$-methylspiperone, ${ }^{18} \mathrm{~F}$-spiperone,

${ }^{18} \mathrm{~F}$-fluorethylspiperone, ${ }^{76} \mathrm{Br}$-bromospiperone, ${ }^{123} \mathrm{I}$-epidepride,

${ }^{123}$ I-iodobenzamide (IBZM)

${ }^{11} \mathrm{C}-\mathrm{BATA}$

${ }^{18} \mathrm{~F}$-2-fluorethoxyidazoxan

${ }^{11} \mathrm{C}$-methyltryptophan

${ }^{11} \mathrm{C}-\mathrm{DASB},{ }^{123} \mathrm{I}-\beta$-CIT

${ }^{11} \mathrm{C}-\mathrm{WAY} 100635$

${ }^{11} \mathrm{C}$-MDL100907, ${ }^{18} \mathrm{~F}$-altanserin, ${ }^{18} \mathrm{~F}$-setoperone

${ }^{11} \mathrm{C}$-MP4A, ${ }^{11} \mathrm{C}$-physostigmine

${ }^{18} \mathrm{~F}$-fluoroethoxybenzovesamicol, ${ }^{11} \mathrm{C}$-vesamicol, ${ }^{123}$ I-benzovesamicol

${ }^{11} \mathrm{C}$-tropanylbenzylate, ${ }^{11} \mathrm{C}-\mathrm{NMPB},{ }^{18} \mathrm{~F}-\mathrm{FP}-\mathrm{TZTP},{ }^{123} \mathrm{I}-\mathrm{QNB}$

${ }^{11} \mathrm{C}-\mathrm{MPA},{ }^{11} \mathrm{C}-\mathrm{A}-85380,{ }^{18} \mathrm{~F}-\mathrm{A}-85380,{ }^{123} \mathrm{I}-\mathrm{A}-85380$

${ }^{11} \mathrm{C}$-dothiepin

${ }^{11} \mathrm{C}$-carfentenil, ${ }^{18} \mathrm{~F}$-cyclofoxy

${ }^{11} \mathrm{C}$-diprenorphine

${ }^{11}$ C-flumazenil

${ }^{11} \mathrm{C}-\mathrm{RO} 15-4513$

${ }^{11} \mathrm{C}-\mathrm{PK} 11195,{ }^{18} \mathrm{~F}-\mathrm{PK} 11195,{ }^{123} \mathrm{I}-\mathrm{PK} 11195$

${ }^{18} \mathrm{~F}-\mathrm{SPARQ},{ }^{11} \mathrm{C}-\mathrm{GR} 205171$

${ }^{11} \mathrm{C}-\mathrm{SCH} 442416$

${ }^{11} \mathrm{C}-\mathrm{CNS} 5161$

${ }^{18}$ F-FDDNP, ${ }^{11} \mathrm{C}$-PIB, ${ }^{11} \mathrm{C}-\mathrm{SB} 13{ }^{123} \mathrm{I}$-IMPY

${ }^{11} \mathrm{C}$-carfentenil reference area devoid of the target receptors may provide a measure of nonspecific binding in certain instances. More complex kinetic models include separate brain compartments representing nonspecific ligand binding, freely exchanging pools, ligand metabolism, and ligand diffusion to binding sites.

At tracer doses, a series of first order rate constants can be used to describe the kinetic behavior of a ligand. Rate constants are obtained by solving the linear simultaneous differential equations describing the kinetics of tracer binding using nonlinear regression analysis. The ratio of the two rate constants describing ligand passage from free to bound brain compartments, $\mathrm{k}_{3} / \mathrm{k}_{4}$, is known as the binding potential (BP) and, at tracer doses of ligands, reflects $f_{2} \cdot B_{\max } / K_{d}$ where $f_{2}$ is the tissue free tracer fraction, $B_{\max }$ the receptor availability, and $\mathrm{K}_{\mathrm{d}}$ the receptor dissociation constant. ${ }^{1}$ Measurement of the BP in the presence of different levels of cold ligand along with conventional Scatchard analysis allows $B_{\max }$ and $K_{d}$ to be independently estimated. As in most neurodegenerative conditions $K_{d}$ appears to remain unchanged, measurements of $\mathrm{BP}$ provide a reflection of changes in $\mathrm{B}_{\max }$ without necessitating displacement studies.

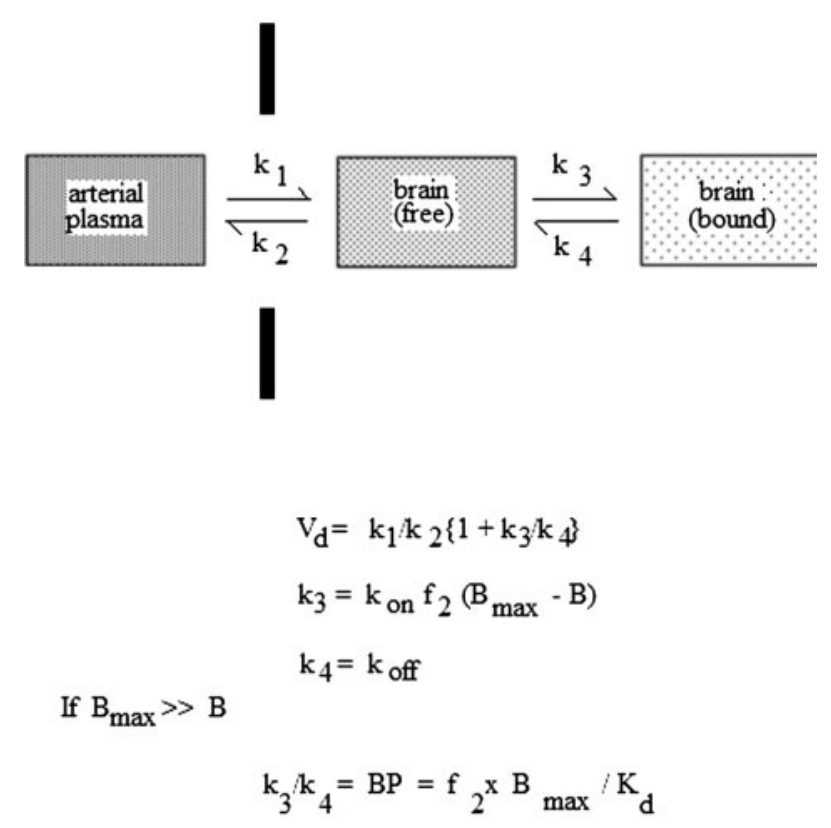

FIG. 1. A two-tissue compartment model describing radiotracer uptake by the brain. All figures are courtesy of the Medical Research Council Clinical Sciences Centre, UK. 
Compartmental modeling requires an input function and regional brain uptake time activity curves (TACs). The input function is generally a metabolite-corrected arterial plasma curve, but, if a nonspecific brain reference area is available (e.g., cerebellum for dopaminergic, $\mathrm{HT}_{1 \mathrm{~A}}$, and NK1 tracers or occipital cortex for opioid tracers), then a brain reference uptake curve can often be substituted for arterial plasma activity as an input function avoiding the need for arterial cannulation. ${ }^{2}$

A problem with conventional compartmental analysis is that it makes a priori assumptions about the number of pharmacological brain compartments present. A way around this problem is to use spectral analysis that estimates the minimum number of kinetic components required to describe regional brain data sets without making any assumptions about their physiological nature. ${ }^{3}$ In essence, the brain tissue function is modeled as a convolution of the measured plasma input function with a sum of $\mathrm{k}$ exponential terms where $\mathrm{k}$ is the number of frequency components required to describe brain uptake. This exponential function is known as an impulse function and, when integrated, yields parametric images of tracer total volume of distributions $\left(\mathrm{V}_{\mathrm{d}}\right)$ which can then be sampled using a conventional region of interest (ROI) approach or subjected to statistical parametric mapping (SPM) - see examples of the use of SPM. Specific $V_{d}$ for a region can be estimated by subtracting the reference area $V_{d}$ from the total $V_{d}$.

Finally, graphical approaches that effectively linearize brain regional TACs when nonspecific uptake has reached a secular equilibrium with plasma can be used. The Patlak approach assumes an irreversibly bound tracer in the specific compartment and derives an influx constant $\mathrm{Ki}$, which reflects the product of the freely exchangeable ligand $\mathrm{V}_{\mathrm{d}}$ and the association rate constant $\mathrm{k}_{3}{ }^{4}$ The Logan plot assumes totally reversible ligand binding and derives the reversible specific $\mathrm{V}_{\mathrm{d}}{ }^{5}$. These graphical approaches have the advantage that they are simpler computationally but the linearization process ignores early time points, tends to crowd time points to one end of the plot, and the fitted gradients can be critically dependent on the end points being accurately measured.

\section{ROI ANALYSIS VERSUS STATISTICAL PARAMETRIC MAPPING}

ROI analysis is conventionally used to sample regional brain levels of tracer uptake and to compare these in normal and pathological situations or before and after blockade with cold ligand. There are, however, a number of problems that arise when the ROI approach is employed: First, a priori assumptions have to be made about the shape and size of ROIs used to sample brain activity. This can, in part, be overcome by coaligning all functional images to the subject's magnetic resonance imaging (MRI) and using the latter to define ROIs; however, brain shape and orientation vary from subject to subject. Second, an a priori selection of the locations of ROIs relevant to the analysis has to be made. One way around this problem is to transform functional images into standard stereotaxic space and apply a predefined template of ROIs from a probabilistic atlas, ${ }^{6}$ although this approach inevitably results in some loss of functional resolution.

An alternative to the use of ROIs for analyzing changes in ligand binding associated with pathological situations or the presence of competitive agents is employment of SPM. ${ }^{7}$ Here, the whole three-dimensional (3D) brain voxel set is considered without any requirement for a priori definition of ROIs. Parametric images of ligand uptake-either influx constants (Ki) or specific volumes of distribution $\left(\mathrm{V}_{\mathrm{d}}\right)$ - are transformed into standard stereotaxic space for each individual; see Figure 2. This can be done using an MRI or brain blood flow template in Montreal Neurological Institute space as provided by the SPM software. Alternatively, a spatial template for the particular radioligand derived from scans of normal subjects can be employed. This last approach has the advantage that, where ligand uptake is concentrated in particular regions, such as the striatum, the accuracy of the spatial normalization is weighted to these areas rather than the cortical rim.

After spatial normalization, group mean images with associated SDs are then generated for each voxel. Tracer binding can subsequently be compared either between different groups of subjects or between an individual subject and a control group. Alternatively, the effects of blocking doses of cold ligands or activating behavioral paradigms on regional tracer binding can be studied. SPM localizes foci of significantly altered $\mathrm{Ki}$ or $\mathrm{V}_{\mathrm{d}}$ at preassigned thresholds (generally $P<0.05$ with a correction for the number of independent multiple comparisons performed) and the magnitude of changes at these foci can then be measured. The SPM approach has the clear advantage that it is exploratory, and so changes in regional ligand binding can be detected that might not have been otherwise predicted. Its disadvantage is the requirement for stereotaxic transformation of $3 \mathrm{D}$ data sets with a consequent loss of functional resolution and a danger of detection of false positives due to the large number of comparisons being performed. The latter can be reduced by the use of masking or small volume correction when a target region is being considered.

\section{DIAGNOSIS OF DEGENERATIVE DISORDERS}

In a longitudinal survey, serial clinical assessments over several years of 134 patients initially thought to have early Alzheimer's disease (AD) were reported to provide a diagnostic sensitivity of $83 \%$ but a specificity 

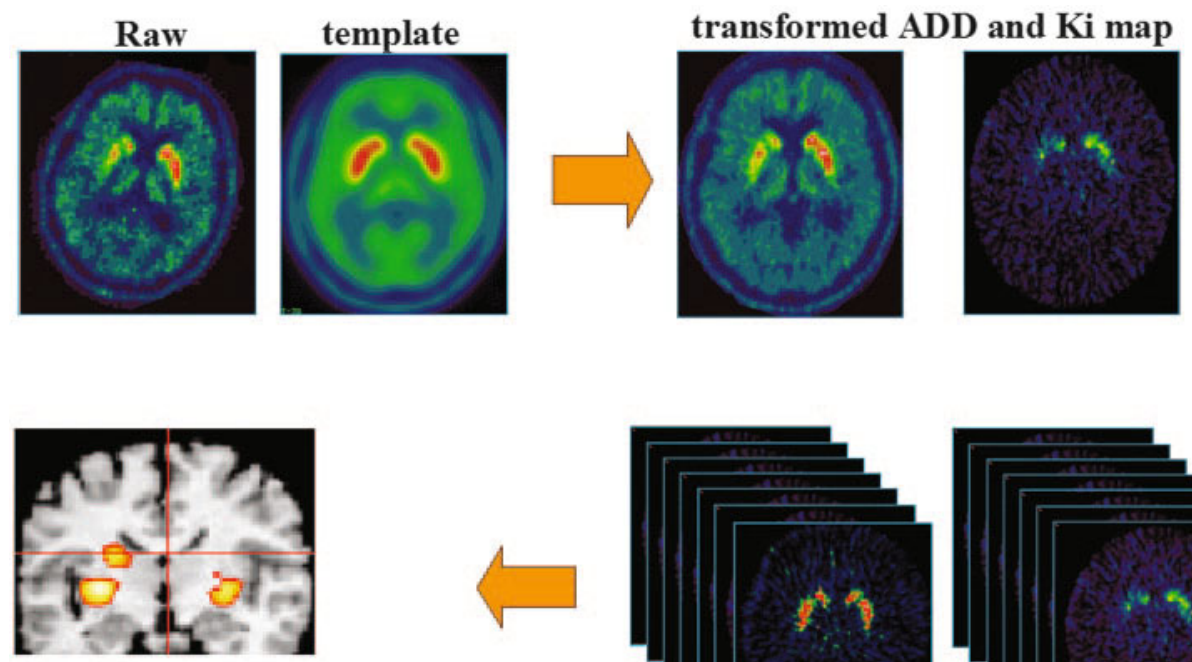

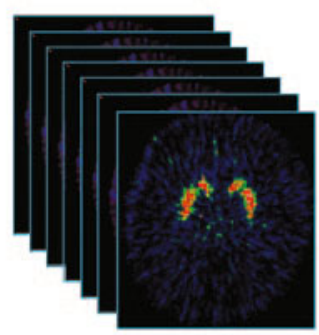

normal

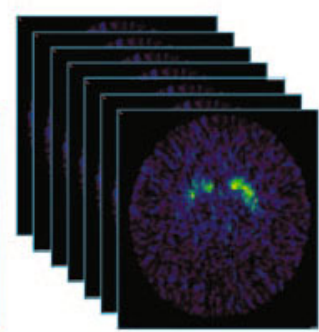

PD

FIG. 2. Spatial transformation of ${ }^{18} \mathrm{~F}$-dopa PET images of a PD patient into standard space using an ${ }^{18} \mathrm{~F}$-dopa template created from 12 normal subjects. Groups of spatially normalized early PD cases and healthy volunteers are then interrogated with statistical parametric mapping. The SPM shows voxels where ${ }^{18} \mathrm{~F}$-dopa uptake is significantly reduced in early PD patients clinically affected on only one side. It can be seen that bilateral disease activity is present.

of only $50 \% .^{8}$ Early AD cases generally show little atrophy on conventional MRI, and formal measurements of hippocampal volume show reductions in only $50 \% .^{9}$ ${ }^{18}$ F-2-fluro-2-deoxyglucose (FDG) PET can demonstrate a characteristic Alzheimer pattern of reduced resting regional cerebral glucose metabolism (rCMRGlc) targeting association temporal and parietal cortex. Adding baseline FDG PET measurements to the assessment of 284 early AD cases (138 with subsequent autopsy diagnosis) was shown to improve diagnostic sensitivity to $93 \%$ and specificity to $73 \% .^{10}$ Such an AD pattern can also be detected when present in amnestic mild cognitive impairment (MCI) cases, so aiding the diagnosis. ${ }^{11}$ Additionally, asymptomatic adult apo- $\epsilon 4$ gene carriers, ${ }^{12}$ identical $\mathrm{AD}$ co-twins, ${ }^{13}$ and subjects with mutations of the amyloid precursor protein or presenilin genes may show subclinical metabolic derangement. ${ }^{14,15}$

Currently there are a number of agents under development designed to prevent amyloid formation (e.g., $\beta$ and $\gamma$ secretase inhibitors) ${ }^{16}$ or to remove plaques (active and passive immunization strategies) in Alzheimer's disease. ${ }^{17}$ To follow the effects of these agents, it would be beneficial to be able to reliably identify the earliest cases of this disorder. Over half of amnestic MCI patients will progress to develop AD on Diagnostic and Statistical Manual of Mental Disorders, fourth edition criteria over 5 years. ${ }^{18}$ The use of FDG PET to screen amnestic MCI for the presence of the characteristic AD pattern of reduced parieto-temporal rCMRGlc has been shown to aid in identifying that minority of cases least likely to progress. ${ }^{19}$
Parkinson's disease (PD) patients show no consistent structural changes on conventional MRI though inversion recovery sequences designed to suppress gray or white matter signals may demonstrate altered nigral structure. ${ }^{20,21}$ In contrast, there is a characteristic asymmetrical pattern of loss of striatal dopamine terminal function in $\mathrm{PD}$, the putamen being more affected than the caudate. ${ }^{22}{ }^{18} \mathrm{~F}$-dopa PET can detect a subclinical parkinsonian pattern of dopaminergic dysfunction in $50 \%$ of asymptomatic adult identical twins ${ }^{23}$ of apparently sporadic PD cases, one quarter of relatives of patients with familial $\mathrm{PD}^{24}$ and, interestingly, in occasional subjects with olfactory dysfunction ${ }^{25}$ and rapid eye movement sleep behavior disorder. ${ }^{26}$

There have been two reported trials involving imaging where de novo cases of PD were recruited with a view to assessing the effects of medication on disease progression. In the REAL PET study, 21 of 183 recruited cases $(11 \%)$ thought to have PD by referring clinicians proved to have normal ${ }^{18} \mathrm{~F}$-dopa PET. ${ }^{27}$ Similarly, in the ELLDOPA trial, 21 out of 135 cases (16\%) felt to have PD had normal ${ }^{123} \mathrm{I}-\beta$ SPECT. ${ }^{28}$ These subjects have now been followed for up to 6 years, and both their clinical syndromes and imaging findings are unchanged. Clearly, if one is interested in testing putative neuroprotective agents in de novo PD, these subjects with normal striatal dopaminergic function would be best excluded given their failure to show progression. Either one has to screen out these cases by imaging dopaminergic function at baseline or allow for a $10-15 \%$ discordance between clinical impression and PET or SPECT assessments of 
striatal dopaminergic function when powering trials to show a given effect size.

\section{DEMONSTRATING MECHANISMS OF DISEASE}

\section{Measuring amyloid load in AD}

Definitive diagnosis of Alzheimer's disease relies on the demonstration of amyloid plaques and neurofibrillary tangles at autopsy. Amyloid plaques are composed of 40to 42 -amino acid amyloid- $\beta$ (A $\beta$ ) peptides. Neurofibrillary tangles contain a hyper-phosphorylated form of the microtubule-associated protein, tau. The time course of amyloid deposition in $\mathrm{AD}$ is uncertain, but post-mortem studies of Down syndrome, a congenital disorder associated with trisomy $21, \mathrm{~A} \beta$ amyloid deposition, and dementia, suggests that amyloid deposition is likely to start a decade before the clinical symptoms of dementia.

The relationship between deposition of $\mathrm{A} \beta$ plaques and cognitive dysfunction in $\mathrm{AD}$ remains uncertain, but a strong link is suggested by the finding that several mutations in the $\mathrm{A} \beta$ precursor protein (APP) gene on chromosome 21 cause early onset $\mathrm{AD} .{ }^{29}$ Although there are a very small number of families affected with this form of $\mathrm{AD}$, this earlier onset disease is phenotypically indistinguishable from the more common later sporadic form of AD. Further genetic support for the amyloid cascade hypothesis comes from the finding that mutations in the presenilin-1 gene on chromosome 14, which codes for a protein that is strongly implicated to be the $\gamma$-secretase enzyme responsible for C-terminal cleavage of $\mathrm{A} \beta$ from its precursor, APP, is associated with early onset $\mathrm{AD}{ }^{30}$

The metabolism of $\mathrm{A} \beta$ has become an important therapeutic target in AD research. Antiamyloid immunization agents ${ }^{17}$ and secretase inhibitors ${ }^{16}$ are being developed and there are now in vivo tools available to directly assess the success of these agents in delaying or reversing amyloid deposition in humans. A demonstration that clinical treatments effectively reduce plaque load while improving cognition will provide valuable proof of concept and strengthen the "amyloid hypothesis" of AD.

There are now three PET imaging agents available that bind to nonphysiological sites in $\beta$-sheeted neuritic amyloid plaques. The first is a nonpolar carbon-11-labeled derivative of the fluorescent dye thioflavin-T. This hydroxybenzothiazole, ${ }^{11} \mathrm{C}$-6-hydroxybenzothiazole-1, also known as ${ }^{11} \mathrm{C}$-PIB (Pittsburgh interesting compound B), showed a significant difference between the retention pattern in $16 \mathrm{AD}$ cases and 9 healthy controls ${ }^{31}$; see Figure 3. Thirteen of the $16 \mathrm{AD}$ cases showed retention of ${ }^{11} \mathrm{C}$-PIB in areas of brain association cortex known to contain large amounts of amyloid deposits, whereas retention was minimal in the cerebellum. Three of the clinically diagnosed AD cases, albeit with normal mini-

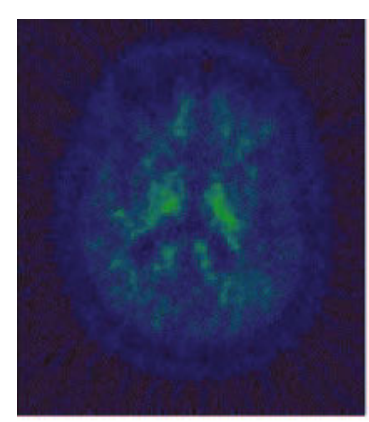

Normal subject

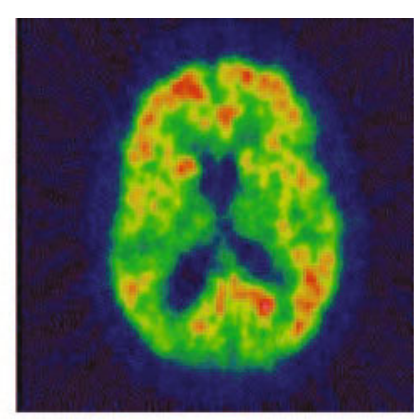

Alzheimer's disease
FIG. 3. ${ }^{11} \mathrm{C}-\mathrm{PIB}$ PET scans obtained from a normal subject and patient with early Alzheimer's disease. The AD case shows widespread amyloid deposition in cortical areas and the striatum.

mental state examination (MMSE) scores, showed no abnormal ${ }^{11} \mathrm{C}$-PIB retention.

The second agent is a naphthol 2-(1- $\left\{6-\left[\left(2-\left[{ }^{18} \mathrm{~F}\right]\right.\right.\right.$ fluoroethyl)(methyl)amino]-2-naphthyl -ethylidene) malononitrile ( $\left.{ }^{18} \mathrm{~F}-\mathrm{FDDNP}\right)$ that, in contrast to ${ }^{11} \mathrm{C}-\mathrm{PIB}$, binds to intracellular neurofibrillary tangles as well as extracellular amyloid plaques. ${ }^{32}$ FDDNP appears to compete with certain nonsteroidal anti-inflammatory agents, such as ibuprofen, for amyloid binding, although this is not true of thioflavins. Temporal lobe ${ }^{18}$ F-FDDNP transit times have been shown to be prolonged in $\mathrm{AD}$ and to correlate with MMSE, verbal, and visual recall scores.

Finally, stilbenes also bind to amyloid plaques. It has been reported that ${ }^{11} \mathrm{C}-4-\mathrm{N}$-methylamino-4' - hydroxystilbene, may be useful as an amyloid PET imaging agent. ${ }^{33}$

\section{Detecting activated microglia}

The isoquinoline ligand PK11195 (1-[2-chlorophenyl]-N-methyl-N-[1-methyl-propyl]-3-isoquinolone carboxamide) binds specifically to the peripheral benzodiazepine binding site (PBBS). The PBBS is expressed by mitochondrial outer membranes in cells of the mononuclear phagocyte lineage. Within the CNS, the PBBS is highly expressed by activated, though not resting, microglia-the brain's intrinsic population of tissue macrophages. ${ }^{34}$ In combination with volumetric MRI to provide detailed structural information, the entantiomeric PET ligand $\left[{ }^{11} \mathrm{C}\right](\mathrm{R})-\mathrm{PK} 11195$ has been used to measure microglial activation in acute and chronic inflammatory, and noninflammatory brain diseases including multiple sclerosis, ${ }^{35}$ herpes encephalitis, ${ }^{36}$ and Rasmussen's encephalitis, ${ }^{37}$ Alzheimer's disease ${ }^{38}$ and frontal dementias, ${ }^{39}$ parkinsonian syndromes, ${ }^{40}$ and motor neurone disease. $^{41}$

The neuronal loss in Alzheimer's disease (AD) is associated with activation of microglial cells whose distribution is closely associated with neuritic amyloid plaques. ${ }^{42}$ It may be that microglia play an active role of in mediating amyloid toxicity by causing secondary tissue damage via release of cytokines such as tumor ne- 

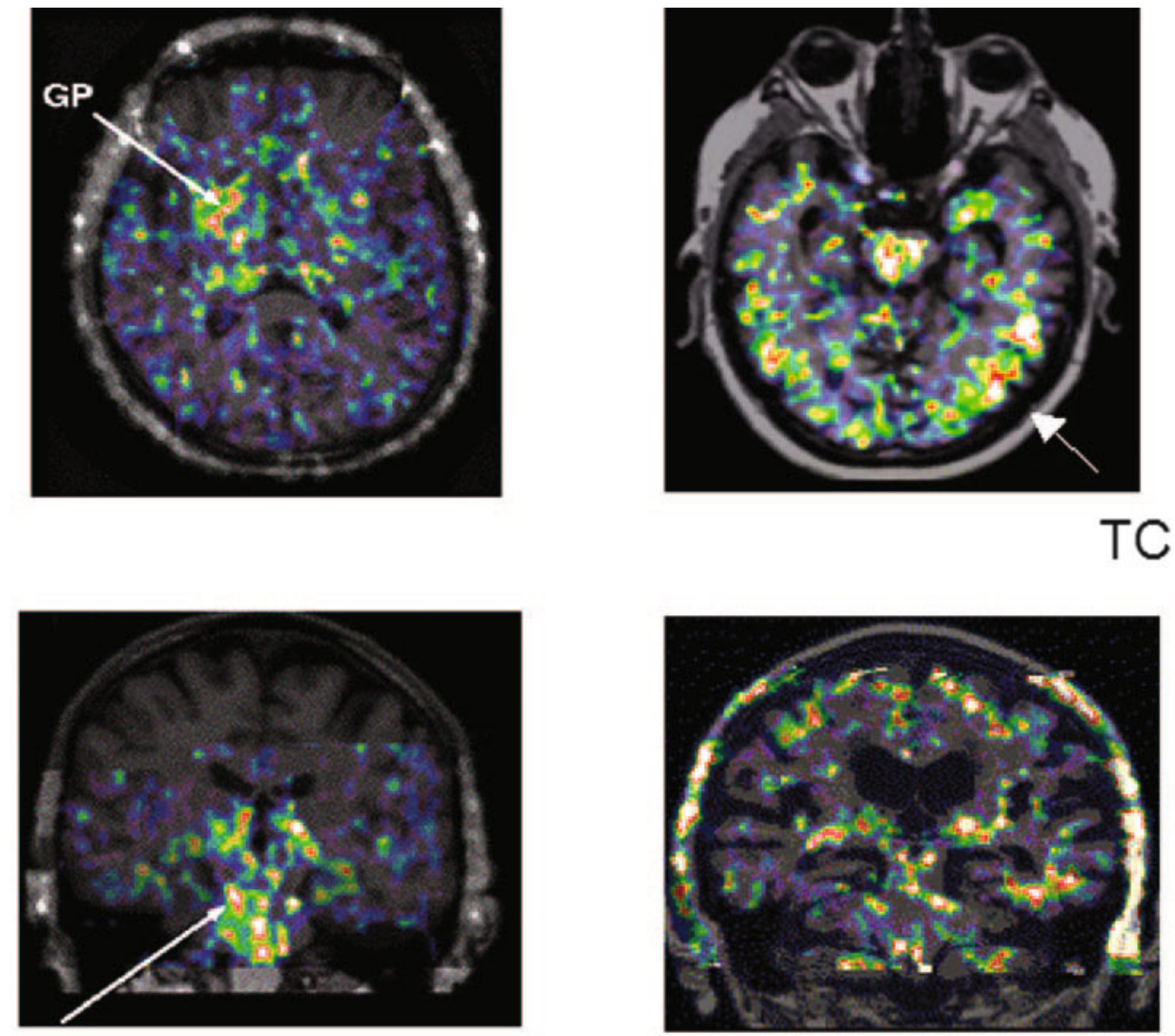

$\mathrm{SN}$

Parkinson's

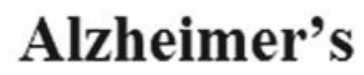

FIG. 4. ${ }^{11} \mathrm{C}-\mathrm{PK} 11195$ PET scans obtained from Parkinson's and Alzheimer's disease cases. Increased microglial activation can be seen in the midbrain and basal ganglia of the PD ( $\mathrm{SN}=$ substantia nigra; GP = globus pallidus) and the cortex (TC = temporal cortex) and brainstem of the $A D$ case.

crosis factor (TNF) $\alpha$ and IL1 $\beta$. They could also mediate adaptive mechanisms via synaptic stripping and remodeling. A recent ${ }^{11} \mathrm{C}-\mathrm{PK} 11195$ PET study reported twofold raised levels of microglial activation in AD temporal cortex; see Figure $4 .{ }^{38}$

Microglial activation has also been detected in the motor cortex and brainstem of patients with amyotrophic lateral sclerosis ${ }^{41}$ and the basal ganglia of patients with both typical and atypical parkinsonian syndromes, ${ }^{40,43}$ being more extensive in the latter. A recent study has reported in abstract that, despite progression of Parkinson's disease, both clinically and as evidenced by ${ }^{18} \mathrm{~F}$ dopa PET, levels of microglial activation remained relatively unchanged over 2 years. ${ }^{44}$

It has been suggested that suppression of the brain's inflammatory and immune reaction to neuronal degeneration may slow the progression of degenerative disease. Agents such as the peroxisome proliferator-activated receptor $\gamma$ agonist minocycline, which are known to suppress microglial activation in cell culture and animal models of disease, are currently in trial. ${ }^{11} \mathrm{C}-\mathrm{PK} 11195$ PET potentially provides a biomarker for examining the anti-inflammatory properties of putative neuroprotective agents in neurodegenerative and neuroinflammatory disorders.

\section{FOLLOWING DISEASE PROGRESSION}

There are a number of difficulties when trying to assess the rate of Parkinson's disease progression clinically. First, timed tests such as finger tapping and hand pronation/supination appear relatively insensitive to progression of early disease though the standing-walkingsitting test is of value. ${ }^{45}$ Second, clinical rating scales such as the Unified Parkinson's Disease Rating Scale (UPDRS) are semiquantitative, subjective, and nonlinear and tend to emphasize particular aspects of the disorder, such as bradykinesia. Third, symptomatic effects of therapies can mask disease progression. PD patients generally require symptomatic medication within months of 
diagnosis and the clinical relief obtained can be profound. Attempts to fully washout such symptomatic effects are poorly tolerated in practice. Additionally, putative neuroprotective agents often turn out to have symptomatic effects-even when these are unsuspected. ${ }^{46}$ A mild symptomatic effect that improves the UPDRS rating by two to three points may be enough to delay the need for dopaminergic drugs by several months. Fourth, when assessing neuroprotective efficacy, it is by no means clear what the best primary endpoint should be. Time to requiring medication or a change of medication can be confounded by drug symptomatic effects as can a predefined absolute or percentage change in rating scales. Time to treatment complications such as dyskinesias and motor fluctuations may reflect dopaminergic drug administration schedules as much as disease progression. ${ }^{47}$

Given these difficulties, there has been an interest in developing imaging biomarkers to follow PD progression. A number of studies have reported that the annual rate of loss of putamen ${ }^{18} \mathrm{~F}$-dopa and ${ }^{123} \mathrm{I}$ - $\beta$-CIT uptake ranges from $7-12 \%$ in early L-dopa-treated cases. ${ }^{45,48-50}$ Trials have now examined relative rates of PD progression in patients randomized to either levodopa or a dopamine agonist. Both the REAL PET $\left({ }^{18} \mathrm{~F} \text {-dopa }\right)^{27}$ and the CALM-PD $\left({ }^{123} \mathrm{I}-\beta \text {-CIT }\right)^{51}$ studies showed a one-third relative slowing of loss of dopamine terminal function in the agonist-treated groups. In contrast, the levodopatreated cohorts showed better clinical outcome rated with the UPDRS, although this finding could have been confounded by symptomatic drug effects given that no washout was performed in the REAL PET study and only an overnight washout in the CALM-PD trial. In contrast, the prevalence of dyskinesias was significantly lower in both the agonist-treated groups.

The imaging findings of the above trials have been criticized on the grounds that the medications concerned may have had differential direct effects on the scanning modalities. ${ }^{52}$ Putamen ${ }^{18} \mathrm{~F}$-dopa uptake reflects dopa decarboxylase activity, which is down-regulated by high doses of dopaminergic agonists and upregulated by antagonists in rodents. ${ }^{53-55}$ Putamen ${ }^{123} \mathrm{I}$ - $\beta$-CIT uptake measures dopamine transporter binding, which becomes reduced following reserpine induced dopamine depletion $^{56}$ and can be increased following levodopa exposure in rats. ${ }^{57-59}$ There are relatively limited data concerning the direct effects of medications on brain ${ }^{18} \mathrm{~F}$-dopa and ${ }^{123} \mathrm{I}-\beta$-CIT uptake. Findings in animal studies have been inconsistent. ${ }^{52,60}$ Human series (albeit small) have failed to show direct drug effects on striatal ${ }^{18} \mathrm{~F}$-dopa and ${ }^{123} \mathrm{I}$ $\beta$-CIT uptake in both normal and PD subjects but these were underpowered to detect subtle changes. Clearly, if imaging is to be used as a biomarker of disease progression, trials will need to build in an assessment of direct medication effects on the modality, possibly by using a randomized delayed wash-in strategy or by recruiting a separate subject group specifically to address this point.

Other degenerative disorders where PET and SPECT may be of potential value in assessing disease progression include Alzheimer's and Huntington's diseases. MRI shows 3-8\% annual changes in hippocampal volume in $\mathrm{AD}^{61}$, whereas FDG PET shows similar annual rates of reduction in temporal and frontal cortex glucose metabolism (rCMRGlc) ${ }^{62,63}$ The annual rate of change of amyloid load in AD has yet to be determined with PET but clearly will be relevant when powering trials to determine the efficacy of antiamyloid agents such as secretase inhibitors. Given the reports of microglial activation in association with immunization against amyloid in $\mathrm{AD}^{17}$ and its murine models, ${ }^{64,65}$ the annual rate of change of levels of microglial activation measured with ${ }^{11}$ C-PK11195 PET may also be of interest.

Huntington's disease is a degenerative disorder currently without any effective therapy and so a fertile area for testing neuroprotective agents. Clinical ratings of severity in this condition are less likely than in PD to be confounded by symptomatic drug effects and the Unified Huntington's Disease Rating Scale (UHDRS) has now been validated. In Huntington's disease, annual reductions in striatal glucose metabolism and dopamine D2 receptor binding have been shown to average 3\% and $6 \%$, respectively. ${ }^{66-69}$ This makes these functional measures a more sensitive marker of HD progression than loss of striatal volume.

\section{DOSE-OCCUPANCY PROFILES}

PET and SPECT can help determine the dose-occupancy profiles of novel ligands for pharma and so help guide dose selection for phase 1 and 2 trials. There are, however, a few caveats: First, there is an inherent assumption that the receptor or enzyme being targeted is relevant to the therapeutic action of the drug. That this may not be the case is illustrated by the use of antidepressants or antipsychotics where symptomatic relief only develops after weeks of exposure to the agent despite high levels of serotonin transporter or dopamine D2 receptor blockade, respectively. Second, this approach only works well for antagonists and partial agonists as full agonists can be therapeutically effective at low levels of receptor occupancy. ${ }^{70}$ Third, it is still not clear what level of receptor or enzyme binding is required to achieve the minimum clinically effective therapeutic dose. Based on experience with classical neuroleptics an occupancy of over $70 \%$ is generally recommended for antagonists, ${ }^{71}$ and this would appear to hold true for other agents such as $\mathrm{NK}^{72}$ and monoamine oxidase B inhibitors. ${ }^{73}$ It has to be said, however, that atypical neuroleptics, such as clozapine, are clinically effective when only occupying $50 \%$ of D2 receptors. ${ }^{74}$ 

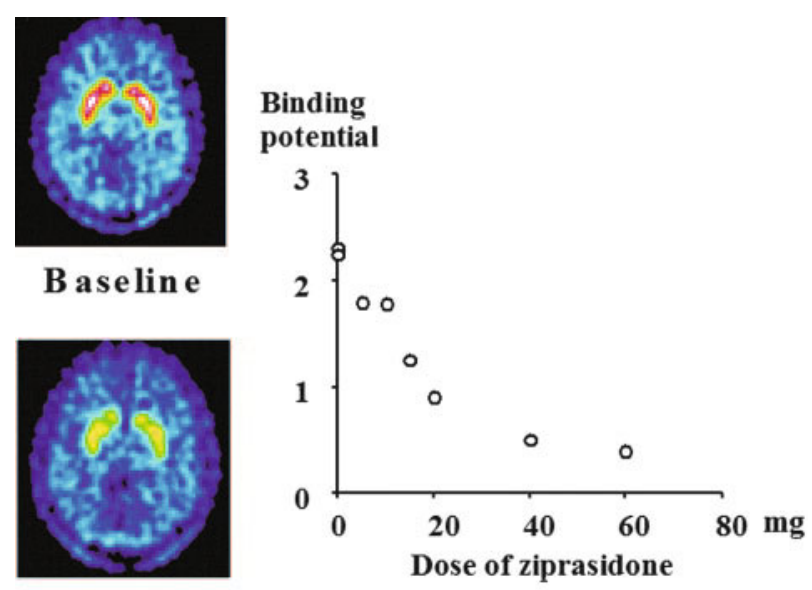

$20 \mathrm{mg}$

FIG. 5. Blockade of striatal ${ }^{11} \mathrm{C}$-raclopride binding by the D2 inhibitor zaprasidone. It can be seen that a $40-\mathrm{mg}$ oral dose of zaprasidone achieves $80 \%$ receptor occupancy. ${ }^{89}$

The next question concerns selection of the radiotracer for evaluating dose-receptor occupancy. Options are to use an established radioligand for the receptor type or subtype under investigation or to radiolabel the novel drug under consideration. The advantage of the first approach is that one is ready to run assuming the radiotracer concerned is freely available for use; see Figure 5. The disadvantage is that the specificity of the novel drug being examined and the radiotracer for the receptor concerned may differ. Radiolabeling a novel drug with ${ }^{11} \mathrm{C}$ or ${ }^{18} \mathrm{~F}$ to produce a PET tracer is generally possible provided a suitable precursor (preferably prepared under GMP conditions) is available. It may, however, take up to 6 months to prepare and validate the new tracer, and not all radiotracers turn out to be useful PET ligands due to their low brain extraction or high nonspecific background signals.

One way of making radiotracer design and selection more efficient involves the concept of microdosing where multiple candidates are prepared as radiotracers and tested simultaneously. ${ }^{75}$ Because subpharmacological doses are being administered $(<20 \mu \mathrm{g})$ on only one or two occasions, the toxicology requirements for administration of these novel radiotracers in man are less stringent than for medicinals. PET can then assess the plasma, regional brain, and other organ pharmacokinetics in man ahead of therapeutic trials. An example of a toxicology package currently provided for a novel radiotracer being administered two to three times in man would be: six rats given $15 \mu \mathrm{g} / \mathrm{kg}$ (100 times human dose) with 3 killed after $48 \mathrm{~h}$ and 3 on day 15. Clinical signs, body weight, pathology on limited list of tissues and genotoxicity (Ames test, mammalian cell mutation assay) are performed.

Pharmaceutical companies often ask for nonhuman primate studies with a novel radioligand before going into man, but these are often not necessary and are expensive in practice. Generally, ex vivo studies in the rat give a good indication of whether a radioligand will make a good tracer, but there are some receptors, such as the NK1 site, which show species sensitivity. Additionally, rodent and primate tracer plasma metabolite profiles can differ. In these situations, monkey studies become valuable. Having said that, microPET is capable of examining in vivo brain binding in the guinea pig and marmoset, which can avoid the need for higher primate studies.

The next question concerns the optimum design of studies to determine dose-occupancy profiles. A typical approach is to start with an open single dose protocol and choose a time to scan after oral drug administration when brain levels are expected to be peaking. When an oral dose has been identified that results in high receptor occupancy the doses can then be successively reduced to establish a dose-occupancy profile at that time point. Subsequently, occupancy at trough plasma levels can be measured by delaying PET to later times following oral dosing while using a dose that gives high occupancy at peak. ${ }^{76}$ Different individuals can be used to establish each baseline and occupancy point on the dose-occupancy profile, or one can use a design combining unoccupied baseline and occupied receptor binding in the same individuals. Generally, establishing baseline receptor availability requires four to eight individuals and each dose occupancy point at least two individuals depending on the interindividual variability.

An alternative, more rigorous approach than the above open design is to blind the study and randomize groups of subjects to different drug doses and placebo. This design, however, is far less flexible than an open design and assumes that one already knows the dose-occupancy profile before starting the study.

As an alternative to a single-dose occupancy design, or following establishment of a peak single dose occupancy profile, a multiple dose paradigm may be employed. Here, the subject is dosed for 1-2 weeks to establish a steady state, and then a trough dose occupancy profile is generated. ${ }^{77}$

\section{EFFECTS OF DRUG ACTION}

An advantage of PET and SPECT is that they can examine the downstream effects of novel agents on brain metabolism and pharmacology. An example of this are the studies with ${ }^{18} \mathrm{~F}$-dopa PET in normal subjects and Parkinson's disease patients before and after administration of the catechol- $O$-methyl transferase inhibitor entacapone with the peripheral dopa decarboxylase inhibitor carbidopa. Four hundred micrograms of entacapone given orally $1 \mathrm{~h}$ before PET boosted levels of striatal ${ }^{18} \mathrm{~F}$-dopa uptake by $50 \%$ in normal and early PD subjects 


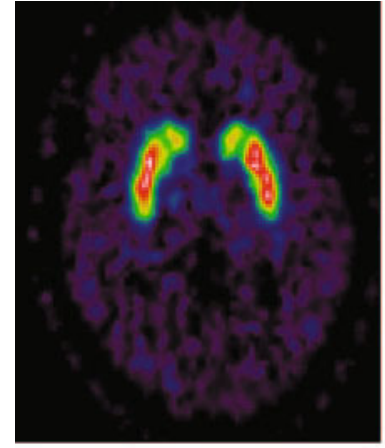

placebo

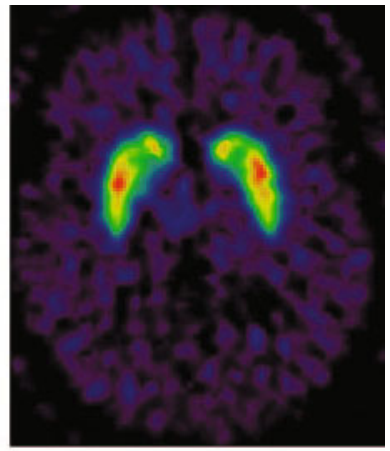

metamphetamine
FIG. 6. Reduction in striatal ${ }^{11} \mathrm{C}$-raclopride binding following intravenous administration of the dopamine releasing agent metamphetamine. A $0.2 \mathrm{mg} / \mathrm{kg}$ bolus of metamphetamine resulted in a $25 \%$ reduction in striatal ${ }^{11} \mathrm{C}$-raclopride binding.

by blocking peripheral metabolism of the tracer. ${ }^{78}$ In advanced PD, the effect was attenuated due to the reduced ability of these patients to store levodopa in the striatum. $^{79}$

An exciting new development of radioisotope imaging is the potential to detect changes in neurotransmitter fluxes. Neurotransmitters that bind to G-coupled receptors, such as dopamine, internalize these receptors transiently after activating them. Radioligands, such as the benzamides ${ }^{11} \mathrm{C}$-raclopride, ${ }^{11} \mathrm{C}-\mathrm{FLB}$, and ${ }^{123} \mathrm{I}-\mathrm{IBZM}$, compete with dopamine for binding to $\mathrm{D} 2$ receptors but can only attach to surface and not internalized sites. As a consequence, the difference in binding of ${ }^{11} \mathrm{C}$-raclopride, ${ }^{11} \mathrm{C}-\mathrm{FLB}$, and ${ }^{123} \mathrm{I}$-IBZM before and after a drug or behavioral challenge gives an indirect measure of changes in synaptic dopamine levels. ${ }^{80}$ This approach has been used to demonstrate that amphetamine ${ }^{81}$ (see FIG. 6), methylphenidate, ${ }^{82}$ and scopolamine, ${ }^{83}$ all increase levels of synaptic dopamine. Fluxes of opioid transmission can be followed using ${ }^{11} \mathrm{C}$-diprenorphine PET. ${ }^{84}$ In the future, it may become possible to examine fluxes of other neurotransmitters acting at G-coupled sites, including glutamate.

An indirect approach for examining drug effects on brain function is to examine changes in patterns of resting or activation-induced blood flow and metabolic changes. FDG PET provides a measure of regional cerebral glucose metabolism (rCMRGlc). Patterns of change in rCMRGlc associated with drug administration give a measure of drug effect and may aid dose selection for clinical trials. ${ }^{85}$ The advantage of this metabolic approach is that it is equally applicable to agonists and antagonists though its utility still remains to be validated. Along similar lines, changes in activation-induced regional cerebral blood flow ( $\mathrm{rCBF}$ ) patterns measured with either $\mathrm{H}_{2}{ }^{15} \mathrm{O}$ PET or functional MRI using the blood oxygen level-dependent (BOLD) effect can be studied before and after a drug challenge. Buspirone has been shown to augment verbal memory induced increases in prefrontal blood flow while these are attenuated by low doses of apomorphine. ${ }^{86}$ Ketamine has been shown to abolish the limbic blood flow response to viewing faces exhibiting a fearful expression. ${ }^{87}$ The HT2c agonist, m-chlorophenylpipermazine (mCPP), increased BOLD signal in the hypothalamus, caudate, pallidum, amygdala and pyriform cortex, anterior cingulate gyrus and choroid plexus. ${ }^{88}$ In a subsequent Go/NoGo task, mCPP enhanced activation in right lateral orbitofrontal cortex. These findings suggest that pharmacologial challenges with $\mathrm{H}_{2}{ }^{15} \mathrm{O}$ PET and fMRI are potentially powerful tools for investigating neurotransmitter function in humans.

\section{CONCLUSIONS}

PET and SPECT imaging can aid drug development by:

- Demonstrating drugs reach their receptor and enzyme targets so providing proof of concept.

- Defining dose occupancy curves for phase 1 and phase 2 studies and so rationalizing choice of dosing in clinical trials.

- Providing biomarkers for monitoring disease progression alongside clinical ratings.

- Monitoring disease mechanisms and measuring inflammation/glial activation in brain disorders.

- Elucidating the downstream effects of drug action.

\section{REFERENCES}

1. Mintun MA, Raichle ME, Kilbourne MR, et al. A quantitative model for the in vivo assessment of drug binding sites with positron emission tomography. Ann Neurol 15:217-227, 1984.

2. Lammertsma AA, Hume SP. Simplified reference tissue model for PET receptor studies. Neuroimage 4:153-158, 1996.

3. Cunningham V, Jones T. Spectral analysis of dynamic PET studies. J Cereb Blood Flow Metab 13:15-23, 1993.

4. Patlak C, Blasberg RG. Graphical evaluation of blood-to-brain transfer constants from multiple-time uptake data. Generalisations. J Cereb Blood Flow Metab 5:584-590, 1985.

5. Logan J, Wolf AP, Shiue CY, Fowler JS. Kinetic modelling of receptor ligand binding applied to positron emission tomographic studies with neuroleptic tracers. J Neurochem 48:73-83, 1986.

6. Hammers A, Allom R, Koepp MJ, et al. Three-dimensional maximum probability atlas of the human brain, with particular reference to the temporal lobe. Hum Brain Mapp 19:224-247, 2003.

7. Friston KJ, Holmes AP, Worsley KJ, et al. Statistical parametric maps in functional imaging: a general linear approach. Hum Brain Mapp 2:189-210, 1995.

8. Lim A, Tsuang D, Kukull W, et al. Clinico-neuropathological correlation of Alzheimer's disease in a community-based case series. J Am Geriatr Soc 47:564-569, 1999.

9. Du AT, Schuff N, Amend D, et al. Magnetic resonance imaging of the entorhinal cortex and hippocampus in mild cognitive impairment and Alzheimer's disease. J Neurol Neurosurg Psychiatry 71:441-447, 2001

10. Silverman DHS, Small GW, Chang CY, et al. Positron emission 
tomography in evaluation of dementia—regional brain metabolism and long-term outcome. JAMA 286:2120-2127, 2001.

11. Silverman DH, Gambhir SS, Huang HW, et al. Evaluating early dementia with and without assessment of regional cerebral metabolism by PET: a comparison of predicted costs and benefits. $\mathrm{J} \mathrm{Nucl}$ Med 43:253-266, 2002.

12. Reiman EM, Caselli RJ, Chen KW, et al. Declining brain activity in cognitively normal apolipoprotein E epsilon 4 heterozygotes: a foundation for using positron emission tomography to efficiently test treatments to prevent Alzheimer's disease. Proc Natl Acad Sci USA 98:3334-3339, 2001.

13. Jarvenpaa T, Raiha I, Kaprio J, et al. Regional cerebral glucose metabolism in monozygotic twins discordant for Alzheimer's disease. Dement Geriatr Cogn Disord 16:245-252, 2003.

14. Kennedy AM, Frackowiak RS, Newman SK, et al. Deficits in cerebral glucose metabolism demonstrated by positron emission tomography in individuals at risk of familial Alzheimer's disease. Neurosci Lett 186:17-20, 1995.

15. Rossor MN, Kennedy AM, Frackowiak RS. Clinical and neuroimaging features of familial Alzheimer's disease. Ann NY Acad Sci 777:49-56, 1996.

16. Xia W. Amyloid inhibitors and Alzheimer's disease. Curr Opin Investig Drugs 4:55-59, 2003.

17. Orgogozo JM, Gilman S, Dartigues JF, et al. Subacute meningoencephalitis in a subset of patients with AD after $A \beta 42$ immunization. Neurology 61:46-54, 2003.

18. Petersen RC. Mild cognitive impairment: transition between aging and Alzheimer's disease. Neurologia 15:93-101, 2000.

19. Arnaiz E, Jelic V, Almkvist O, et al. Impaired cerebral glucose metabolism and cognitive functioning predict deterioration in mild cognitive impairment. Neuroreport 12:851-855, 2001.

20. Hutchinson M, Raff U. Structural changes of the substantia nigra in Parkinson's disease as revealed by MR imaging. AJNR Am J Neuroradiol 21:697-701, 2000.

21. Hu MT, White SJ, Herlihy AH, et al. A comparison of (18)F-dopa PET and inversion recovery MRI in the diagnosis of Parkinson's disease. Neurology 56:1195-1200, 2001.

22. Morrish PK, Sawle GV, Brooks DJ. Clinical and [18F]dopa PET findings in early Parkinson's disease. J Neurol Neurosurg Psychiat 59:597-600, 1995.

23. Piccini P, Burn DJ, Ceravalo R, et al. The role of inheritance in sporadic Parkinson's disease: evidence from a longitudinal study of dopaminergic function in twins. Ann Neurol 45:577-582, 1999.

24. Piccini P, Morrish PK, Turjanski N, et al. Dopaminergic function in familial Parkinson's disease: a clinical and 18F-dopa PET study. Ann Neurol 41:222-229, 1997.

25. Ponsen MM, Stoffers D, Booij J, et al. Idiopathic hyposmia as a preclinical sign of Parkinson's disease. Ann Neurol 56:173-181, 2004.

26. Eisensehr I, Linke R, Noachtar S, et al. Reduced striatal dopamine transporters in idiopathic rapid eye movement sleep behaviour disorder-comparison with Parkinson's disease and controls. Brain 123:1155-1160, 2000

27. Whone AL, Watts RL, Stoessl J, et al. Slower progression of PD with ropinirol versus L-dopa: the REAL-PET study. Ann Neurol 54:93-101, 2003.

28. Parkinson Study Group. Does levodopa slow or hasten the rate of progression of Parkinson disease? The results of the ELLDOPA trial. Neurology 60(Suppl 1):A80-A81, 2003.

29. Hutton M, Perez-Tur J, Hardy J. Genetics of Alzheimer's disease. Essays Biochem 33:117-131, 1998.

30. Kennedy AM, Newman SK, Frackowiak RSJ, et al. Chromosome-14 linked familial Alzheimers disease-a clinicopathological study of a single pedigree. Brain 118:185-205, 1995.

31. Klunk WE, Engler H, Nordberg A, et al. Imaging brain amyloid in Alzheimer's disease with Pittsburgh Compound-B. Ann Neurol 55:306-319, 2004.

32. Shoghi-Jadid K, Small GW, Agdeppa ED, et al. Localization of neurofibrillary tangles and $\beta$-amyloid plaques in the brains of living patients with Alzheimer disease. Am J Geriatr Psychiatry 10:24-35, 2002.

33. Kung HF, Lee CW, Zhuang ZP, et al. Novel stilbenes as probes for amyloid plaques. J Am Chem Soc 123:12740-12741, 2001.
34. Stephenson DT, Schober DA, Smalstig EB, et al. Peripheral benzodiazepine receptors are colocalized with activated microglia following transient global forebrain ischemia in the rat. $J$ Neurosci 15:5263-5274, 1995

35. Banati RB, Newcombe J, Gunn RN, et al. The peripheral benzodiazepine binding site in the brain in multiple sclerosis: quantitative in vivo imaging of microglia as a measure of disease activity. Brain 123(Pt 11):2321-2337, 2000.

36. Cagnin A, Myers R, Gunn RN, et al. In vivo visualization of activated glia by $11 \mathrm{C}(\mathrm{R})$-PK11195-PET following herpes encephalitis reveals projected neuronal damage beyond the primary focal lesion. Brain 124:2014-2027, 2001.

37. Banati RB, Goerres GW, Myers R, et al. [11C](R)-PK11195 positron emission tomography imaging of activated microglia in vivo in Rasmussen's encephalitis. Neurology 53:2199-2203, 1999.

38. Cagnin A, Brooks DJ, Kennedy AM, et al. In-vivo measurement of activated microglia in dementia. Lancet 358:461-467, 2001.

39. Cagnin A, Brooks DJ, Rossor M, et al. In vivo detection of activated microglia in frontotemporal dementia: A PET study. Neurology 58(Suppl 3):A144-A145, 2002.

40. Gerhard A, Banati RB, Goerres GB, et al. [(11)C](R)-PK11195 PET imaging of microglial activation in multiple system atrophy. Neurology 61:686-689, 2003.

41. Turner MR, Cagnin A, Turkheimer FE, et al. Evidence of widespread cerebral microglial activation in amyotrophic lateral sclerosis: an $[11 \mathrm{C}](\mathrm{R})-\mathrm{PK} 11195$ positron emission tomography study. Neurobiol Dis 15:601-609, 2004.

42. Banati RB, Gehrmann J, Czech C, et al. Early and rapid de novo synthesis of Alzheimer $\beta$ A4-amyloid precursor protein (APP) in activated microglia. Glia 9:199-210, 1993.

43. Gerhard A, Banati RB, Cagnin A, Brooks DJ. In vivo imaging of activated microglia with [C-11]PK11195 positron emission tomography (PET) in idiopathic and atypical Parkinson's disease. Neurology 56(Suppl 3):A270, 2001.

44. Gerhard AP, Pavese N, Hotton GR, Es M, Turkheimer F, Oertel W, Banati RB, Brooks DJ Microglial activation in Parkinson's diseaseits longitudinal course and correlation with clinical parameters: an [11C](R)—PK11195 PET study. Neurology 62:A432, 2004.

45. Morrish PK, Sawle GV, Brooks DJ. An [18F]dopa PET and clinical study of the rate of progression in Parkinson's disease. Brain 119:585-591, 1996.

46. Penney JB, Oakes D, Shoulson I, et al. Impact of deprenyl and tocopherol treatment on Parkinson's disease in DATATOP patients requiring levodopa. Ann Neurol 39:37-45, 1996.

47. Olanow CW, Schapira AHV, Rascol O. Continuous dopaminereceptor stimulation in early Parkinson's disease. Trends Neurosci 23:S117-S126, 2000.

48. Morrish PK, Rakshi JS, Sawle GV, Brooks DJ. Measuring the rate of progression and estimating the preclinical period of Parkinson's disease with [18F]dopa PET. J Neurol Neurosurg Psychiatry 64: 314-319, 1998.

49. Marek K, Innis R, van Dyck C, et al. [123I] $\beta$-CIT SPECT imaging assessment of the rate of Parkinson's disease progression. Neurology 57:2089-2094, 2001

50. Nurmi E, Ruottinen HM, Bergman J, et al. Rate of progression in Parkinson's disease: a 6-[18F]fluoro-L-dopa PET study. Mov Disord 16:608-615, 2001.

51. Parkinson Study Group. Dopamine transporter brain imaging to assess the effects of Pramipexole vs levodopa Parkinson disease progression. JAMA 287:1653-1661, 2002.

52. Ahlskog JE. Slowing Parkinson's disease progression: recent dopamine agonist trials. Neurology 60:381-389, 2003.

53. Hadjiconstantinou M, Wemlinger TA, Sylvia CP, et al. Aromatic L-amino acid decarboxylase activity of mouse striatum is modulated via dopamine receptors. J Neurochem 60:2175-2180, 1993.

54. Zhu MY, Juorio AV, Paterson IA, Boulton AA. Regulation of striatal aromatic L-amino acid decarboxylase: effects of blockade or activation of dopamine receptors. Eur J Pharmacol 238:157164, 1993

55. Melamed E, Globus M, Friedlender E, Rosenthal J. Chronic Ldopa administration decreases striatal accumulation of dopamine from exogenous L-dopa in rats with intact nigrostriatal projections. Neurology 33:950-953, 1983. 
56. Kim SE, Scheffel U, Boja JW, Kuhar MJ. Effect of reserpine on binding of H-3 WIN-35,428 to dopamine uptake sites. J Nucl Med 35:199P, 1994.

57. Ikawa K, Watanabe A, Kaneno S, Toru M. Modulation of $[3 \mathrm{H}]$ mazindol binding sites in rat striatum by dopaminergic agents. Eur J Pharmacol 250:261-266, 1993.

58. Rioux L, Frohna PA, Joyce JN, Schneider JS. The effects of chronic levodopa treatment on pre- and postsynaptic markers of dopaminergic function in striatum of parkinsonian monkeys. Mov Disord 12:148-158, 1997.

59. Murer MG, Dziewczapolski G, Menalled LB, et al. Chronic levodopa is not toxic for remaining dopamine neurons, but instead promotes their recovery, in rats with moderate nigrostriatal lesions. Ann Neurol 43:561-575, 1998.

60. Brooks DJ, Frey KA, Marek KL, et al. Assessment of neuroimaging techniques as biomarkers of the progression of Parkinson's disease. Exp Neurol 184:S68-S79, 2003.

61. Du AT, Schuff N, Kramer JH, et al. Higher atrophy rate of entorhinal cortex than hippocampus in AD. Neurology 62:422-427, 2004.

62. Grady CL, Haxby JV, Horwitz B, et al. Longitudinal study of the early neuropsychological and cerebral metabolic changes in dementia of the Alzheimer type. J Clin Exp Neuropsychol 10:576596, 1988.

63. Haxby JV, Grady CL, Koss E, et al. Longitudinal study of cerebral metabolic asymmetries and associated neuropsychological patterns in early dementia of the Alzheimer type. Arch Neurol 47:753-760, 1990.

64. Ferrer I, Boada Rovira M, Sanchez Guerra ML, et al. Neuropathology and pathogenesis of encephalitis following amyloid- $\beta$ immunization in Alzheimer's disease. Brain Pathol 14:11-20, 2004.

65. Wilcock DM, Munireddy SK, Rosenthal A, et al. Microglial activation facilitates $A \beta$ plaque removal following intracranial anti-A $\beta$ antibody administration. Neurobiol Dis 15:11-20, 2004.

66. Antonini A, Leenders KL, Eidelberg D. [C-11]Raclopride-PET studies of the Huntington's disease rate of progression: relevance of the trinucleotide repeat length. Ann Neurol 43:253-255, 1998.

67. Antonini A, Leenders KL, Spiegel R, et al. Striatal glucose metabolism and dopamine D-2 receptor binding in asymptomatic gene carriers and patients with Huntington's disease. Brain 119: 2085-2095, 1996.

68. Grafton ST, Mazziotta JC, Pahl JJ, et al. Serial changes of glucose cerebral metabolism and caudate size in persons at risk for Huntington's disease. Arch Neurol 49:1161-1167, 1992.

69. Andrews TC, Weeks RA, Turjanski N, et al. Huntington's disease progression PET and clinical observations. Brain 122:2353-2363, 1999.

70. Antonini A, Schwarz J, Oertel WH, et al. [11C]raclopride and positron emission tomography in previously untreated patients with Parkinson's disease: influence of L-dopa and lisuride therapy on striatal dopamine D2-receptors. Neurology 44:1325-1329, 1994.

71. Farde L, Wiesel F, Halldin C, Sedvall G. Central D2 dopamine receptor occupancy in schizophrenic patients treated with antipsychotic drugs. Arch Gen Psychiatry 45:71-76, 1988.

72. Bergstrom M, Hargreaves RJ, Burns HD, et al. Human positron emission tomography studies of brain neurokinin 1 receptor occupancy by aprepitant. Biol Psychiatry 55:1007-1012, 2004.

73. Bench CJ, Price GW, Lammertsma AA, et al. Measurement of human cerebral monoamine oxidase type B (MAO-B) activity with positron emission tomography (PET): a dose ranging study with the reversible inhibitor Ro 19-6327. Eur J Clin Pharmacol 40: 169-173, 1991.

74. Farde L, Wiesel FA, Nordstrom AL, et al. D1 and D2 dopamine receptor occupancy during treatment with conventional and atypical neuroleptics. Psychopharmacology 99:28s-31s, 1989.

75. Bergstrom M, Grahnen A, Langstrom B. Positron emission tomography microdosing: a new concept with application in tracer and early clinical drug development. Eur J Clin Pharmacol 59:357366, 2003.

76. Bench CJ, Lammertsma AA, Grasby PM, et al. The time course of binding to striatal dopamine D2 receptors by the neuroleptic ziprasidone (CP-88,059-01) determined by positron emission tomography. Psychopharmacology (Berl) 124:141-147, 1996.

77. Bergstrom M, Westerberg G, Nemeth G, et al. MAO-A inhibition in brain after dosing with esuprone, moclobemide and placebo in healthy volunteers: in vivo studies with positron emission tomography. Eur J Clin Pharmacol 52:121-128, 1997.

78. Sawle GV, Burn DJ, Morrish PK, et al. The effect of entacapone (OR-611) on brain [18F]-6-L-fluorodopa metabolism: implications for levodopa therapy of Parkinson's disease. Neurology 44:12921297, 1994.

79. Ruottinen HM, Niinivirta M, Bergman J, et al. Detection of response to COMT inhibition in FDOPA PET in advanced Parkinson's disease requires prolonged imaging. Synapse 40:19-26, 2001.

80. Laruelle M. Imaging synaptic neurotransmission with in vivo binding competition techniques: a critical review. J Cereb Blood Flow Metab 20:423-451, 2000.

81. Piccini P, Pavese N, Brooks DJ. Endogenous dopamine release after pharmacological challenges in Parkinson's disease. Ann Neurol 53:647-653, 2003.

82. Volkow ND, Wang G, Fowler JS, et al. Therapeutic doses of oral methylphenidate significantly increase extracellular dopamine in the human brain. J Neurosci 21:RC121, 2001.

83. Dewey SL, Smith GS, Logan J, et al. Effects of central cholinergic blockade on striatal dopamine release measured with positron emission tomography in normal human subjects. Proc Natl Acad Sci USA 90:11816-11820, 1993.

84. Koepp MJ, Richardson MP, Duncan JS, Brooks DJ. Focal cortical release of endogenous opioids during reading-induced seizures. Lancet 352:952-955, 1998.

85. McCulloch J, Kelly PAT, Ford I. Effect of apomorphine on the relationship between local cerebral glucose utilisation and local cerebral blood flow (with an appendix on its statistical analysis). J Cereb Blood Flow Metab 2:487-499, 1982.

86. Grasby PM, Friston KJ, Bench CJ, et al. The effect of apomorphine and buspirone on regional cerebral blood flow during the performance of a cognitive task-measuring neuromodulatory effects of psychotropic drugs in man. Eur J Neurosci 4:1203-1212, 1992.

87. Abel KM, Allin MP, Kucharska-Pietura K, et al. Ketamine alters neural processing of facial emotion recognition in healthy men: an fMRI study. Neuroreport 14:387-391, 2003.

88. Anderson IM, Clark L, Elliott R, et al. 5-HT(2C) receptor activation by m-chlorophenylpipermazine detected in humans with fMRI. Neuroreport 13:1547-1551, 2002.

89. Bench CJ, Lammertsma AA, Dolan RJ, et al. Dose dependent occupancy of central dopamine D2 receptors by the novel neuroleptic CP-88,059-01: a study using positron emission tomography and 11C-raclopride. Psychopharmacology (Berl) 112:308-314, 1993. 